\title{
Headache prevalence and its characterization amongst hospital workers in Enugu, South East Nigeria
}

\author{
Ikenna Onwuekwe ${ }^{1}$, Tonia Onyeka ${ }^{2 *}$, Emmanuel Aguwa ${ }^{3}$, Birinus Ezeala-Adikaibe ${ }^{1}$, Oluchi Ekenze ${ }^{1}$
} and Elias Onuora ${ }^{4}$

\begin{abstract}
Background: Headaches are probably the commonest neurological complaint worldwide. Amongst workers it contributes significantly to loss of productive time and work efficiency. It is an important cause of disability and reduced quality of life. The prevalence and pattern amongst health workers in Africa has not been extensively studied.

Objective: This epidemiological sampling-based preliminary study examined the frequency and pattern of headache in a population of health workers of a tertiary hospital in Enugu, South East Nigeria.

Methods: Study participants, recruited by balloting, completed a self-administered questionnaire to screen for headache and its associations (defined as headache unrelated to fever and experienced within 6 months prior to the date the questionnaire was administered). Data analysis was by SPSS version 16. Ethical approval was obtained from the Hospital Ethical Review Committee.

Results: One hundred and thirty-three workers aged $18-70$ years, were evaluated (males 53.4\%, $\mathrm{n}=71$ and females $46.6 \%, n=62$ ). Headache was experienced by $88 \%$ of workers with primary headaches constituting more than $70 \%$ of cases. Females were more affected in both instances. Primary and secondary headaches occurred more in younger and older workers respectively and the association was significant $(P<0.05)$. Headaches were not a significant cause of disability and loss of productivity.
\end{abstract}

Conclusion: Headaches are very prevalent in hospital workers in Enugu, Nigeria. In older workers screening for underlying causes is indicated. Disability, work absenteeism and loss of productive time are minimal despite the high headache prevalence.

Keywords: Headache, Pattern, Health workers, Nigeria

\section{Introduction}

Headache is the commonest neurological disorder in the community with variable intensity, ranging from a trivial nuisance to a severe, disabling, acute or chronic disorder, and may impose a substantial burden on sufferers and on society $[1,2]$. It is one of the commonest reasons for visiting the neurology clinics worldwide [3-5], exerting significant burden on its sufferers and impairing daily function especially when accompanied by other symptoms, hence

\footnotetext{
* Correspondence: doctortoniaonyeka@gmail.com

${ }^{2}$ Department of Anaesthesia/Pain \& Palliative Care Unit, University of Nigeria

Teaching Hospital, Ituku-Ozalla, PMB 01129 Enugu, Nigeria

Full list of author information is available at the end of the article
}

adversely affecting quality of life [6]. According to the World Health Organisation (WHO), $1.7-4 \%$ of the adult population of the world have headaches on 15 or more days every month [7] and a lifetime prevalence of more than $90 \%$ has been attributed to headache disorders in most populations of the world [8].

It is known that Africans have a higher threshold for pain and may not present to the clinic just for an 'ordinary headache' [9]. Local experiences show that patients suffering from other chronic neurological disorders present very late to doctors and sometimes never do so [9]. Chronic headaches produce individual and societal burdens, the former referring to its effect on family, social and 
recreational activities and the latter referring to effects on healthcare cost (direct costs) and work and function (indirect costs), including absenteeism and reduced effectiveness [10].

There is limited data for headache prevalence in Africa. In 2004, the 1-year prevalence of headache from a doorto-door survey of rural south Tanzania was $23.1 \%$ (18.8\% males and $26.4 \%$ females) [11]. Getahu and colleagues in Ethiopia found a 1-year prevalence rate of 73.2\% [12]. A 1992 study from Ibadan, South West Nigeria, found the crude life-time prevalence for at least one episode of headache to be $51 \%$ [13].

In Nigeria, there is a paucity of data on the national prevalence and burden of chronic headaches [14] despite the fact that it is the commonest presenting neurological disorder in the authors' environment $[1,3]$, and therefore the possibility that a big headache problem exists in Nigeria. There are also no known studies of the prevalence and characterization of headache among Nigerian healthcare workers or healthcare workers in South East Nigeria hence the relevance of this study.

\section{Aim of the study}

The aim of this preliminary study was to determine the frequency and pattern of headaches among a population of healthcare workers in a tertiary health institution located in South East Nigeria.

\section{Methods}

This was an epidemiological sampling-based study (Figure 1) using a semi-structured questionnaire. The questionnaire was pre-tested in another health facility at Nsukka (a local government area similar to the study area) for content validity. English language was used to reduce cross- cultural misinterpretations and wrong understanding of terms.

The questionnaire was self- administered to all various cadres of health workers in medical unit of University of Nigeria Teaching Hospital, a tertiary health institution located in Enugu, South- East Nigeria, over a 3- month period from September - November 2013, selected by simple random method out of the various units in the hospital e.g. surgical, medical, laboratory, physiotherapy, nutrition, administrative, laundry, transport, security, and medical record. Within these are various cadres of hospital staff: physicians, nurses, pharmacists and cleaners. Out of a total of 141 only 133 gave consent and hence were studied, giving a response rate of $94.3 \%$. To ascertain the overall prevalence of headache, subjects were asked if they have ever had a headache within the previous six months and to note any association. They were to rate the severity of headache based on a scale of mild, moderate and severe. The impact of these severe headaches on the daily activity and the number of days they occur in a month were recorded. The character of the pain, location,

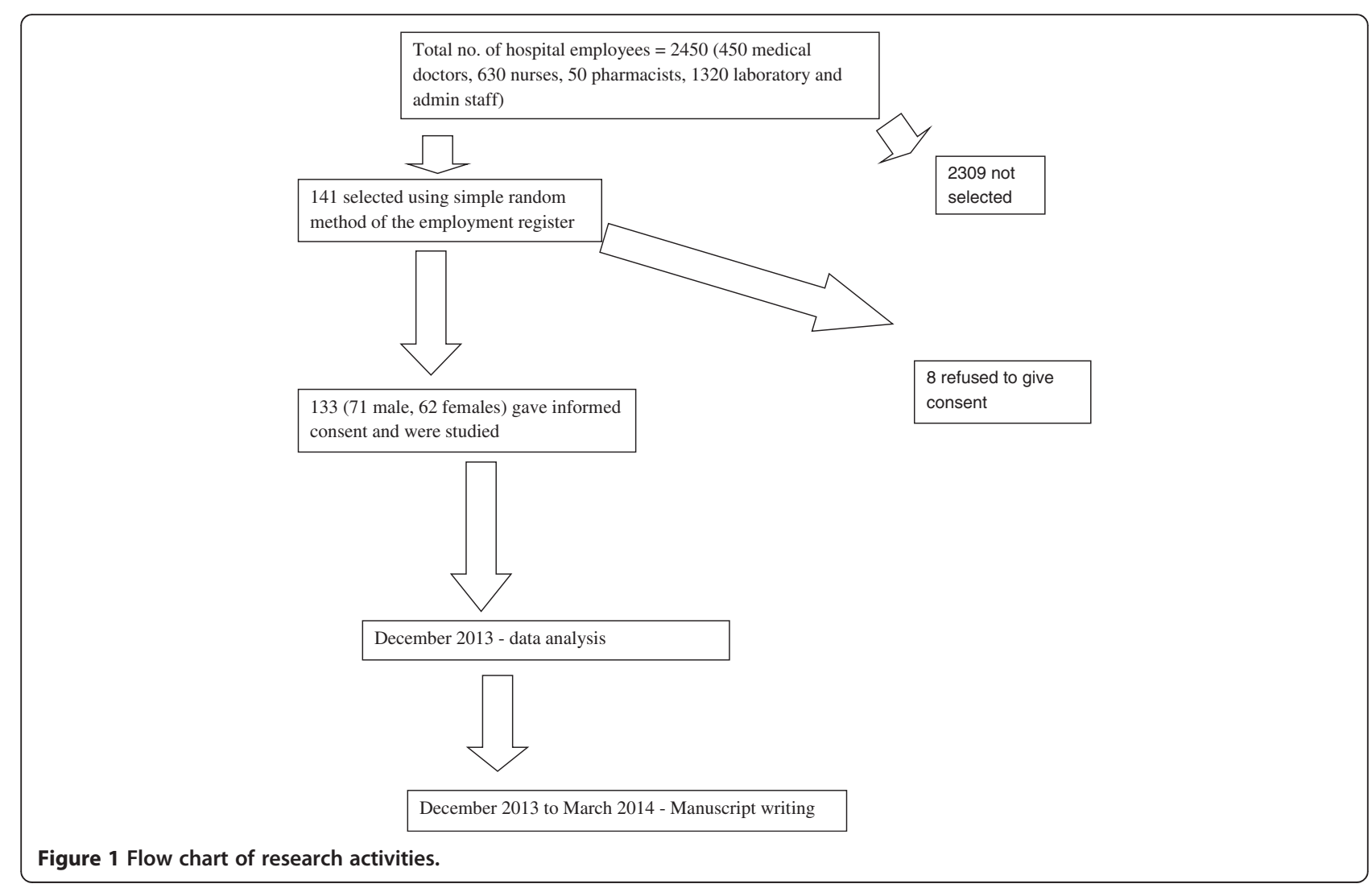


duration, and the total numbers of times in the 6 months preceding the date of administering the questionnaire were also noted.

Statistical Package for Social Sciences version 16 was used in statistical analysis. Comparison of multiplex groups was carried out with One Way ANOVA test. On the other hand comparison of two distinct groups was carried out with student $t$ test. Chi-square test (and/or Fisher's exact test) was used in analysis of categorical variables. The results were revealed as mean $\pm \mathrm{SD}$. P value $<0.05$ was interpreted as statistically meaningful. Ethical approval was obtained from the hospital ethics committee.

\section{Results}

Of the 2,450 hospital employees (450 medical doctors, 630 nurses, 50 pharmacists, and 1320 laboratory and administrative staff), 141 were selected using simple random method from the employment register and eventually only 133 health workers (71 males and 62 females) gave informed consent and were studied (response rate 94.3\%). More of the respondents were males (53.4\%) and most were within the 25 - 34 years age group (46.6\%). Most of the workers had worked for only $\leq 5$ years $(72.9 \%)$. Table 1 illustrates.

The prevalence of headache in the past 6 months was $88.0 \%$ (among males the prevalence was $87.3 \%$ while in

Table 1 Demographic distribution and work experience of health workers

\begin{tabular}{|c|c|c|}
\hline Variable & Frequency & Percent \\
\hline \multicolumn{3}{|l|}{ Sex } \\
\hline Male & 71 & 53.4 \\
\hline Female & 62 & 46.6 \\
\hline Total & 133 & 100.0 \\
\hline \multicolumn{3}{|l|}{ Age Group } \\
\hline $15-24$ & 13 & 9.8 \\
\hline $25-34$ & 62 & 46.6 \\
\hline $35-44$ & 36 & 27.1 \\
\hline $45-54$ & 15 & 11.3 \\
\hline $55-64$ & 6 & 4.5 \\
\hline 65 and above & 1 & 0.7 \\
\hline Total & 133 & 100.0 \\
\hline \multicolumn{3}{|c|}{ Number of years worked } \\
\hline $1-5$ & 97 & 72.9 \\
\hline $6-10$ & 18 & 13.5 \\
\hline $11-15$ & 7 & 5.3 \\
\hline $16-20$ & 4 & 3.0 \\
\hline $21-25$ & 5 & 3.8 \\
\hline $26-30$ & 2 & 1.5 \\
\hline Total & 133 & 100.0 \\
\hline
\end{tabular}

females it was $88.7 \%$ ). There was no significant difference observed between the sexes $(p=0.806)$. In both sexes, primary headaches were more prevalent $(71.0 \%$ in males and $76.4 \%$ in females). There was also no significant difference in the prevalence of the primary headaches among the sexes $(\mathrm{p}=0.509)$. See Table 2 .

Most respondents reported $\leq 5$ episodes of headache in the last 6 months $(74.4 \%)$ and these were typically of short-lasting durations, $<60$ minutes $(44.4 \%)$. There was no observed periodicity to the headaches in $57.3 \%$ of cases (see Table 3). Most of the headaches were not located in any particular part of the head or side-locked (71.7\%); were described as mildly severe in $59.8 \%$ of cases while $88.0 \%$ of respondents did not suffer any sleep disruption. The headaches were often not significantly disabling $(73.4 \%)$ and in $93.2 \%$ of respondents did not lead to absenteeism or affect productivity at work (Table 4).

Stress (35.0\%) and head trauma/illness/infection (18.8\%) were the commonest predisposing conditions to the headache (Table 5). Refractive errors were present in $16.2 \%$ of respondents with headaches. In $25.6 \%$ there were headache prodromes and these included irritability (10.3\%) and fatigue (5.1\%). During the headaches, associated symptoms occurred in $30.8 \%$ of respondents and these included nasal congestion, redness of eyes, sinusitis or allergies (26.5\%) as depicted in Table 6. In most cases, there was no known family history of migraines or other chronic headaches (Figure 2).

Management of headache was varied among respondents. In most cases (47.9\%) no intervention was required. However in other instances, investigations (11.1\%) and eye

Table 2 Prevalence of headache among the health workers

\begin{tabular}{lcc}
\hline \multicolumn{3}{c}{ General prevalence of headache in the past $\mathbf{~}$ months } \\
\hline Variables & Frequency & Percent \\
\hline Headache present & 117 & 88.0 \\
Headache absent & 16 & 12.0 \\
& Sex prevalence of headache & \\
& Male (\%) & Female (\%) \\
Headache present & $62(87.3)$ & $55(88.7)$ \\
Headache absent & $9(12.7)$ & $7(11.3)$ \\
Total & $71(100.0)$ & $62(100.0)$ \\
& $X^{2}=0.060 ;$ P value $=0.806$ & \\
Type of headache & $44(71.0)$ & $42(76.4)$ \\
Primary & $18(29.0)$ & $13(23.6)$ \\
*Secondary & $62(100.0)$ & \\
Total & $X^{2}=0.436 ;$ P value $=0.509$ &
\end{tabular}

* Secondary headache is headache with a definitive and identifiable cause found for it i.e. those with pre-existing conditions that may cause the headache e.g. hypertension, cervical spondylosis, refractive error, sleep apnoea, malaria and other febrile conditions [15]. 
Table 3 Characterization of the headaches

\begin{tabular}{|c|c|c|}
\hline Variable/Characteristics & $\begin{array}{l}\text { Frequency } \\
(\mathrm{N}=117)\end{array}$ & Percent \\
\hline \multicolumn{3}{|c|}{ Number of episodes in past 6 months } \\
\hline $1-5$ & 87 & 74.4 \\
\hline $6-10$ & 25 & 21.4 \\
\hline $11-15$ & 3 & 2.6 \\
\hline $16-20$ & 2 & 1.6 \\
\hline \multicolumn{3}{|c|}{ Usual duration of headaches } \\
\hline Seconds & 19 & 16.2 \\
\hline Minutes & 52 & 44.4 \\
\hline Hours & 36 & 30.9 \\
\hline Days & 10 & 8.5 \\
\hline \multicolumn{3}{|c|}{ Usual time of day of the headache } \\
\hline Morning & 18 & 15.4 \\
\hline Afternoon & 15 & 12.8 \\
\hline Night & 13 & 11.1 \\
\hline Continuous & 4 & 3.4 \\
\hline No particular time & 67 & 57.3 \\
\hline \multicolumn{3}{|c|}{$\begin{array}{l}\text { Is the headache becoming stronger, } \\
\text { last longer or occur more frequent? }\end{array}$} \\
\hline Yes & 22 & 18.8 \\
\hline No & 95 & 81.2 \\
\hline \multicolumn{3}{|c|}{$\begin{array}{l}\text { What is the commonest nature of the } \\
\text { headache? }\end{array}$} \\
\hline Throbbing/exploding & 43 & 36.8 \\
\hline Sharp & 4 & 3.4 \\
\hline Tightness & 5 & 4.3 \\
\hline Dull & 6 & 5.1 \\
\hline Aching & 24 & 20.5 \\
\hline Pressure in head & 32 & 27.3 \\
\hline Grinding & 3 & 2.6 \\
\hline
\end{tabular}

checks $(7.7 \%)$ were done. The over-the counter- available analgesic, paracetamol, $(83.8 \%)$ was the commonest treatment received (Table 7).

The health workers' ages did not significantly affect both the presence and treatment of headache $(\mathrm{p}=0.483$ and 0.293 respectively) but significantly affected the type of headache $(\mathrm{p}=0.005)$ i.e. whether it was primary or secondary headache (Table 8 ). Years of working in the hospital did not significantly affect the prevalence of headache $(P=0.123)$, type of headache $(P=0.423)$ or treatment of the headaches $(\mathrm{P}=0.535)$ as shown in Table 9 . There was no correlation between the number of headache episodes and the number of years worked in the hospital [Pearson Correlation $(r)=-0.066$ ] or age of the health worker $[r=0.001]$.
Table 4 Usual location and severity of the headache

\begin{tabular}{|c|c|c|}
\hline Usual Location of headache & Frequency & Percent \\
\hline Left side & 3 & 2.6 \\
\hline Forehead & 9 & 7.7 \\
\hline Around the head/ill-defined & 11 & 9.4 \\
\hline Right side & 2 & 1.7 \\
\hline Both Temples & 2 & 1.7 \\
\hline Top of the head & 1 & 0.9 \\
\hline Neck & 2 & 1.7 \\
\hline Back of head & 3 & 2.6 \\
\hline No particular side & 84 & 71.7 \\
\hline \multicolumn{3}{|l|}{ Severity of headache } \\
\hline Mild & 70 & 59.8 \\
\hline Moderate & 45 & 38.5 \\
\hline severe & 2 & 1.7 \\
\hline \multicolumn{3}{|c|}{$\begin{array}{l}\text { Is the headache strong enough to wake } \\
\text { you from sleep? }\end{array}$} \\
\hline Yes & 14 & 12.0 \\
\hline No & 103 & 88.0 \\
\hline \multicolumn{3}{|c|}{ Effect of headache on daily activities } \\
\hline No significant disability & 16 & 13.7 \\
\hline Mild disability & 86 & 73.4 \\
\hline Moderate & 3 & 2.6 \\
\hline Severe disability & 12 & 10.3 \\
\hline \multicolumn{3}{|c|}{$\begin{array}{l}\text { Headache -related work absenteeism } \\
\text { or reduced productivity? }\end{array}$} \\
\hline Yes & 8 & 6.8 \\
\hline No & 109 & 93.2 \\
\hline
\end{tabular}

\section{Discussion}

Headache is the commonest presenting neurological disorder in most communities and clinical settings worldwide $[2,12]$. Studies from Nigeria, including Enugu, also support this $[1,3,13]$. The prevalence of headache in health care workers has been variously reported from Western countries $[16,17]$ but there is a paucity of similar data from Nigeria and Africa. There was an inability to assess headaches as distinctly experienced in the various cadres of hospital workers and it was also not possible in this study to ascertain distinct headache entities and their roles. Other limitations of this study were its small sample size, the possibility of recall bias arising from patients' answers to occurrences of headaches in the past 6 months, and use of a 3-point pain scale instead of the 10-point Visual Analogue Scale (VAS) which has greater scale refinement and discrimination power. VAS has been noted to be a valid instrument for measurement of pain intensity in patients with headaches [18].

A prevalence of $88.0 \%$ was obtained for headaches amongst the hospital workers, with slightly higher rates 
Table 5 Predisposing conditions to the headache

\begin{tabular}{lcc}
\hline Factors preceding the headache & Frequency (N =117) & Percent \\
\hline Accident, illness or infection & 22 & 18.8 \\
Odours & 5 & 4.3 \\
Fatigue & 34 & 29.1 \\
School & 2 & 1.7 \\
Hunger & 17 & 14.5 \\
Noise & 4 & 3.4 \\
Stress & 41 & 35.0 \\
Exercise & 1 & 0.9 \\
Family problem & 2 & 1.7 \\
Menstrual flow & 2 & 1.7 \\
Lack of sleep & 8 & 6.8 \\
Hot weather & 2 & 1.7 \\
None & 49 & 41.9 \\
$\quad$ Existing chronic medical conditions that & may cause headache \\
Hypertension & 10 & 8.5 \\
Cervical spondylosis & 3 & 2.6 \\
Refractive errors & 19 & 16.2 \\
Diabetes mellitus & 2 & 1.7 \\
Sleep apnoea & 1 & 0.9 \\
None & 97 & 82.9 \\
\hline Note that some respondents fill mo than & &
\end{tabular}

Note that some respondents filled more than one option.

in females than males. Though the study periods vary, the figure compares favourably with the rate of $84.4 \%$ obtained amongst from health workers in the United States [16] but is significantly higher than the $54.7 \%$ and 27.1\% prevalence rates obtained from Italian and Turkish health workers respectively $[16,19]$. A survey of headache in Ethiopian textile workers found a prevalence of 73\% [12]. The headache prevalence of $88 \%$ for hospital workers in this study compares favourably with the $88.3 \%$ prevalence found in a study of medical students in the same locality [20]. The prevalence is also higher than the community prevalence rates of $51 \%$ and $23.1 \%$ seen in Ibadan, South West Nigeria and rural south Tanzania respectively $[11,13]$. It is possible that the different figures may reflect a combination of environmental challenges, durations of study and varied survey instruments used.

It is well noted that females tend to have higher rates for headache prevalence across cultures and continents $[1,3,12,16,17,19]$ and while this seemed to be the case in our study, the difference was not statistically significant. Reasons adduced for the higher female prevalence include the influence of oestrogens and progesterone on headaches after menarche and the greater propensity for females to seek medical attention for headaches [21].

Most of our subjects had probable primary headaches although no further attempts were made in this study to distinguish between the various different types (which
Table 6 Headache prodromes and other features associated with the headaches

\begin{tabular}{|c|c|c|}
\hline & $\begin{array}{l}\text { Frequency } \\
(\mathrm{N}=117)\end{array}$ & Percent \\
\hline \multicolumn{3}{|l|}{ Presence of warning signs before headache } \\
\hline Yes & 30 & 25.6 \\
\hline No & 87 & 74.4 \\
\hline \multicolumn{3}{|l|}{ Warning signs } \\
\hline Pallor & 1 & 0.9 \\
\hline Mood swing & 6 & 5.1 \\
\hline Irritability & 12 & 10.3 \\
\hline Dizziness & 3 & 2.6 \\
\hline Tired/sleepy & 6 & 5.1 \\
\hline Rings around the eyes & 1 & 0.9 \\
\hline Hyperactivity & 1 & 0.9 \\
\hline Eye problems & 2 & 1.7 \\
\hline None & 104 & 88.9 \\
\hline \multicolumn{3}{|c|}{ Other symptoms associated with the headaches } \\
\hline \multicolumn{3}{|l|}{$\begin{array}{l}\text { Presence of other symptoms during the } \\
\text { headaches }\end{array}$} \\
\hline Yes & 36 & 30.8 \\
\hline No & 81 & 69.2 \\
\hline $\begin{array}{l}\text { Nasal congestion, redness of eyes, sinusitis } \\
\text { or allergies associated with the headache }\end{array}$ & 31 & 26.5 \\
\hline Nausea. & 2 & 1.7 \\
\hline Stomach pain & 9 & 7.7 \\
\hline Vomiting & 1 & 0.9 \\
\hline Confusion & 3 & 2.6 \\
\hline Numbness in arms and legs & 6 & 5.1 \\
\hline Diarrhoea & 1 & 0.9 \\
\hline Dropping of the eyes & 1 & 0.9 \\
\hline Fever & 12 & 10.3 \\
\hline
\end{tabular}

Note that some respondents filled more than one option.

include the trigeminal associated cephalalgias (TACs), migraine and tension- type headaches). Headaches were of short duration ( $<60$ minutes) and were not side -locked in most instances unlike the longer duration ( $>6$ hours) migraine headaches noted in the Turkish study [19]. Migraine headache prevalence rate is uniformly low across much of Africa but was found to be significantly high in a cohort of textile mill workers in Ethiopia [12,22].

Stress, probably related to challenges in the work environment, played the greatest role (35.0\%) in this study and this reflected in the calming role attributed to relaxation techniques utilized by the health workers (40.2\%) to manage their headaches. Besides life and work stress, personality traits such as aggression, anger and type A behaviour are factors that may aggravate stress and are 


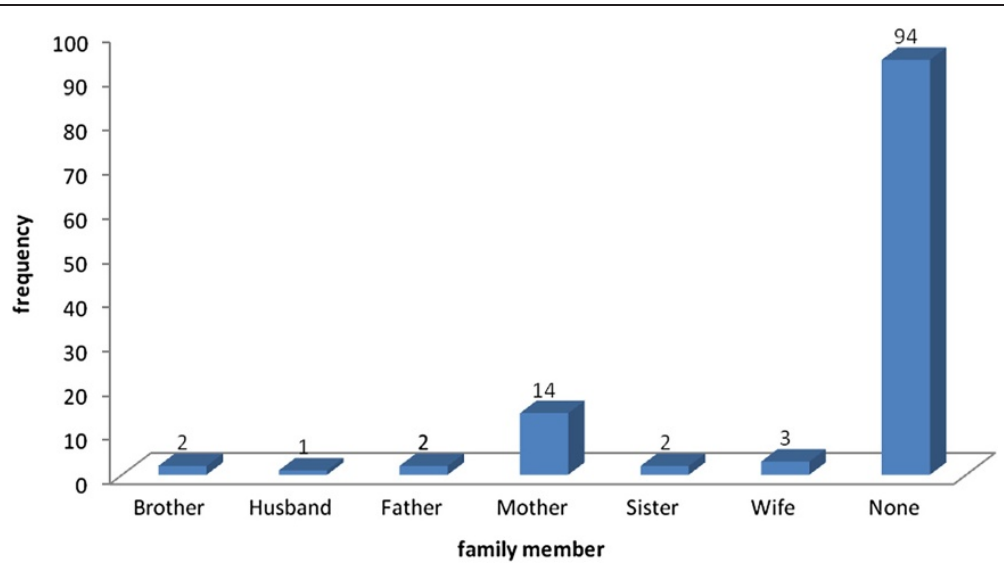

Figure 2 Family member with history of headaches, migraines, sick headaches, motion sickness or had trouble taking birth control pills because of headaches.

Table 7 Management received for the last headache episode

\begin{tabular}{|c|c|c|}
\hline Management actions & Frequency $(N=117)$ & Percent \\
\hline \multicolumn{3}{|l|}{ Headache was managed by - } \\
\hline Health worker & 19 & 16.2 \\
\hline Self & 42 & 35.9 \\
\hline No treatment received & 56 & 47.9 \\
\hline \multicolumn{3}{|l|}{ A. Investigations done } \\
\hline Laboratory & 13 & 11.1 \\
\hline Eye check & 9 & 7.7 \\
\hline \multicolumn{3}{|l|}{ B. Treatment received } \\
\hline Anti-malaria & 7 & 6.0 \\
\hline Ergotamine & 1 & 0.9 \\
\hline Food & 1 & 0.9 \\
\hline Ibuprofen & 5 & 4.3 \\
\hline Other NSAIDs* & 2 & 1.7 \\
\hline Paracetamol & 98 & 83.8 \\
\hline Tramadol (narcotic analgesic) & 1 & 0.9 \\
\hline Eye glasses were prescribed & 16 & 13.7 \\
\hline Relaxation & 1 & 0.9 \\
\hline \multicolumn{3}{|c|}{ Other actions that relieve the headaches } \\
\hline Cold compress & 13 & 11.1 \\
\hline Eating & 20 & 17.1 \\
\hline Massage & 3 & 2.6 \\
\hline Moving around & 3 & 2.6 \\
\hline Relaxation & 47 & 40.2 \\
\hline Sleep & 31 & 26.5 \\
\hline Vomiting & 1 & 0.9 \\
\hline Others & 1 & 0.9 \\
\hline
\end{tabular}

*NSAIDs = non-steroidal anti-inflammatory agents. Note that some respondents filled more than one option. frequently found in headache patients but were not sought for in this study [22-24].

There was no significant association or correlation found between the prevalence of headaches and years of working experience in this study. Non-pharmacological treatment was suitable for almost half of respondents (47.9\%) while the over-the -counter medicine, paracetamol, was the most utilised drug treatment. This finding is essentially similar to that of health workers with headaches in the Unites States but contrasts with the use of NSAIDs in a Turkey study $[17,19]$. Despite working in a health facility, self-medication was commonly practised (35.9\%) but this was even more significant among Turkish health workers (54.6\%) [19].

The low rate of medical consultation for headache in hospital workers is of interest. In this study centre, headache ranks low among the disorders seen at both the Pain Clinic and Neurology Clinic accounting for only $2.7 \%$ of all neurological cases seen in the latter and $9^{\text {th }}$ of the top 10 disorders encountered [3]. Some reasons adduced for the low rate of presentations to clinics for headaches as well as low rates of success in headache treatment amongst Africans include underdiagnoses or misdiagnoses due to lack of adequate knowledge by healthcare professionals, headache sufferers being ignorant of effective prophylaxis and treatment, perception of headaches as a trivial problem, and great tolerance to pain [25-29]. Other reasons include poor healthcare facilities [30], low economic power [25], gender/child discrimination [28], and unavailability of effective medication $[28,29]$. The authors are of the opinion that African patients' preference for/reliance on non-drug options (complementary and alternative medicine, CAM) $[25,28,30]$ for pain relief may also be contributory.

Of important economic interest is the rarity of absenteeism from work or loss of productive time as reported in this study. These factors are important because many 
Table 8 Age group and management of headache

\begin{tabular}{|c|c|c|c|c|c|c|}
\hline \multirow[b]{2}{*}{ Variables } & \multicolumn{6}{|c|}{ Age group in years } \\
\hline & $15-24$ & $25-34$ & $35-44$ & $45-54$ & $55-64$ & $\leq 65$ \\
\hline \multicolumn{7}{|l|}{ Presence of headache } \\
\hline Yes & 12(92.3) & $53(85.5)$ & $34(94.4)$ & 13(86.7) & $4(66.7)$ & $1(100.0)$ \\
\hline No & $1(7.7)$ & $9(14.5)$ & 2(5.6) & $2(23.3)$ & $2(33.3)$ & $0(0.0)$ \\
\hline Total & $13(100.0)$ & $62(100.0)$ & $36(100.0)$ & 15(100.0) & $6(100.0)$ & $1(100.0)$ \\
\hline \multicolumn{7}{|c|}{ Likelihood-ratio $X^{2}=4.480 ; P$ value $=0.483$} \\
\hline \multicolumn{7}{|l|}{ Type of headache } \\
\hline Primary & $7(58.3)$ & $45(84.9)$ & 27(79.4) & $6(46.2)$ & $1(33.3)$ & $0(0.0)$ \\
\hline Secondary & $5(41.7)$ & $8(15.1)$ & $7(20.6)$ & $7(53.8)$ & $3(66.7)$ & $1(100.0)$ \\
\hline Total & $12(100.0)$ & $53(100.0)$ & $34(100.0)$ & 13(100.0) & $4(100.0)$ & 1(100.0) \\
\hline \multicolumn{7}{|c|}{ Likelihood-ratio $X^{2}=16.995 ; P$ value $=0.005$ (significant) } \\
\hline \multicolumn{7}{|c|}{ Treatment of headache } \\
\hline Other health worker & 10(83.3) & $33(62.3)$ & 18(52.9) & 10(76.9) & $3(66.7)$ & 1(100.0) \\
\hline Self & $2(16.7)$ & 20(37.7) & $16(47.1)$ & $3(23.1)$ & 1(33.3) & $0(0.0)$ \\
\hline Total & $12(100.0)$ & $53(100.0)$ & $34(100.0)$ & 13(100.0) & $4(100.0)$ & $1(100.0)$ \\
\hline \multicolumn{7}{|c|}{ Likelihood-ratio $X^{2}=6.135 ; \mathrm{P}$ value $=0.293$} \\
\hline
\end{tabular}

headache sufferers are at the peak of their work-productive life [26]. Employers may lose an average of 12 days per year because of an employee headache syndrome [27]. The authors relate reason for the rarity of work absenteeism and loss of productive time to the majority of headaches being of a mild nature with low disabling rates. A similar negligible rate of absenteeism was the outcome among Italian health workers with headache [16].

Table 9 Number of years worked in the hospital and management of headache

\begin{tabular}{|c|c|c|c|}
\hline \multirow[b]{2}{*}{ Variables } & \multicolumn{3}{|c|}{ Number of years worked in the hospital } \\
\hline & $1-10$ & $11-20$ & $21-30$ \\
\hline \multicolumn{4}{|l|}{ Presence of headache } \\
\hline Yes & $101(87.8)$ & $11(100.0)$ & $5(71.4)$ \\
\hline No & $14(12.2)$ & $0(0.0)$ & $2(28.6)$ \\
\hline Total & 115(100.0) & 11(100.0) & $7(100.0)$ \\
\hline \multicolumn{4}{|c|}{ Likelihood-ratio $X^{2}=4.199 ; P$ value $=0.123$} \\
\hline \multicolumn{4}{|l|}{ Type of headache } \\
\hline Primary & $75(65.2)$ & $8(72.7)$ & $3(42.9)$ \\
\hline Secondary & 40(34.8) & $3(27.3)$ & $4(57.1)$ \\
\hline Total & 115(100.0) & $11(100.0)$ & $7(100.0)$ \\
\hline \multicolumn{4}{|c|}{ Likelihood-ratio $x^{2}=1.719 ; P$ value $=0.423$} \\
\hline \multicolumn{4}{|c|}{ Treatment of headache } \\
\hline Other health worker & $78(67.8)$ & $7(63.6)$ & $6(85.7)$ \\
\hline Self & $37(32.2)$ & $4(36.4)$ & $1(14.3)$ \\
\hline Total & 115(100.0) & 11(100.0) & $7(100.0)$ \\
\hline \multicolumn{4}{|c|}{ Likelihood-ratio $X^{2}=1.250 ; P$ value $=0.535$} \\
\hline
\end{tabular}

\section{Conclusion}

This preliminary study has revealed headaches to be common in this community of healthcare workers. However, the seemingly low effect of headache on health workers productivity in this study, despite its high prevalence rate and contrary to views [28] from other African studies, is of notable relief in a developing economy like Nigeria where health indicators are unimpressive and medical services still face huge challenges. In addition, presentation to Pain or Neurology clinic for headache disorders by respondents in this study has been shown to be low, demonstrating the need for increased and continuous health awareness on headache disorders as well as enhanced occupational health services in Nigerian hospitals. By the findings of this work, the authors encourage more robust studies on headache disorders among healthcare workers in African countries with a view to informing better practice decisions and reducing the global headache burden.

\section{Competing interest}

The authors declare that they have no competing interests.

Authors' contributions

TO and $1 \mathrm{O}$ conceptualised the study; TO, IO, EA, BE, OE and EO designed the questionnaire and collected data; TO, EA and $I O$ analysed the data; all authors participated in drafting the manuscript; all authors read and approved the final manuscript.

Acknowledgement

The authors are grateful to Dr. Ada Shirley for her co-operation with data collection.

\section{Declaration}

This study was not supported by a grant. 


\section{Author details}

${ }^{1}$ Neurology Unit, Department of Medicine, University of Nigeria Teaching Hospital, Ituku-Ozalla, Enugu, Nigeria. ²Department of Anaesthesia/Pain \& Palliative Care Unit, University of Nigeria Teaching Hospital, Ituku-Ozalla, PMB 01129 Enugu, Nigeria. ${ }^{3}$ Department of Community Medicine, University of Nigeria Teaching Hospital, Ituku-Ozalla, Enugu, Nigeria. ${ }^{4}$ Department of Anaesthesia, University of Nigeria Teaching Hospital, Ituku-Ozalla, Enugu, Nigeria.

Received: 4 August 2014 Accepted: 11 November 2014

Published: 25 November 2014

\section{References}

1. Onwuekwe IO, Ezeala-Adikaibe B, Ekenze OS: Neurological disease burden in two semi-urban communities in South East Nigeria. Nig J Med 2012, 1(3):317-319.

2. Scher AL, Stewart WF, Lipton RB: Migraine and headache: a meta-analytic approach. In Epidemiology of Pain. Edited by Crombie IK, Croft PR, Linton SJ. Seattle: IASP Press; 1999:159-170.

3. Onwuekwe 1O, Ezeala-Adikaibe B: Prevalence and distribution of neurological disease in a Neurology Clinic in Enugu, Nigeria. Annals Med Health Science Res 2011, 1(1):63-68.

4. Vas J, Rebollo A, Perea-Milla E, Mendez C, Font C, Gomez-Rio M, Martin-Avila M, Cabrera-Iboleon J, Caballero MD, Olmos MA, Aguilar I, Faus V, Martos F: Study protocol for a pragmatic randomised controlled trial in general practice investigating the effectiveness of acupuncture against migraine. BMC Compl Alternative Med 2008, 8:12.

5. Fowler TJ, Scadding JW: Introduction. In Clinical Neurology. 3rd edition. Edited by Fowler TJ, Scadding JE. London: Arnold; 2003:1-20.

6. Manack AN, Buse DC, Lipton RB: Chronic migraine: epidemiology and disease burden. Curr Pain Headache Rep 2011, 15(1):70-78.

7. World Health Organisation (WHO): Headache Disorders; 2014. Available at: http://www.who.int/mediacentre/factsheets/fs277/en/ [Accessed 31 May 2014]

8. Pinder RM: Migraine - a suitable case for treatment? Neuropsychiatr Dis Treat 2006, 2(3):245-246.

9. Patel V, Simbine AP, Soares IC, Weiss HA, Wheeler E: Prevalence of severe mental and neurological disorders in Mozambique: a population-based survey. Lancet 2007, 370(9592):1055-1060.

10. Hu H, Markson LE, Lipton RB, Stewart WF, Berger ML: Burden of migraine in the United States: disability and economic costs. Arch Intern Med 1999, 159:813-818.

11. Dent W, Spiss HK, Helbok R, Matuja WBP, Sheunemann S, Schmutzard E: Prevalence of migraine in a rural area in South Tanzania: a door-to-door survey. Cephalalgia 2004, 24:960-966.

12. Takele GM, Haimanot RT, Martelleti P: Prevalence and burden of headache in Akaki Textile Mill Workers, Ethiopia. J Headache Pain 2008, 9(2):119-128.

13. Osuntokun BO, Adeuja AO, Nottidge VA, Bademosi O, Olumide AO, Ige $O$, Yaria F, Schoenberg BS, Bolis CL: Prevalence of headache and migrainous headache in Nigerian Africans: a community-based study. East Afr Med $\mathrm{J}$ 1992, 69(4):196-199.

14. Owolabi LF, Gwaram B: Clinical Profile of Primary Headache disorders in Kano, Northwestern Nigeria. J Med Tropics 2012, 14(2):109-115

15. ICHD: International classification of headache disorders (ICHD) 3rd edition (beta version). Cephalalgia 2013, 33:629-808.

16. Hughes MD, Wu J, Williams TC, Loberger JM, Hudson MF, Burdine JR, Wagner PJ: The experience of headaches in health care workers: opportunity for care improvement. Headache 2013, 53(6):962-969.

17. Sokolovic E, Riederer F, Szucs T, Agosti R, Sandor PS: Self-reported headache among the employees of a Swiss University Hospital: prevalence, disability, current treatment and economic impact. J Headache Pain 2013, 14:29.

18. Lundqvist C, Benth JS, Grande RB, Aaseth K, Russel MB: A vertical VAS is a valid instrument for monitoring headache pain intensity. Cephalalgia 2009, 29(10):1034-1041.

19. Dikici S, Baltaci D, Arslan G, Atar G, Ercan N, Yilmaz A, Kara $\mid H$ : Headache frequency among the health care workers and the relationship working conditions. Abant Med J 2013, 2(2):106-113.

20. Ezeala-Adikaibe B, Ekenze OS, Onwuekwe IO, Ulasi II: Frequency and pattern of headache among medical students at Enugu, South East Nigeria. Nig J Med 2012, 21(2):205-208.

21. Martin BC, Dorfman JH, McMillan CA: Prevalence of migraine headache and association with sex, age, race, and rural/urban residence: a population-based study of Georgia Medicaid recipients. Clin Ther 1994, 16:854-872.

22. Sjösten $N$, Nabi $H$, Westerlund $H$, Singh-Manoux A, Dartigues J, Goldberg M, Zins M, Oksanen T, Salo P, Pentti J, Kivimäki M, Vahtera J: Influence of retirement and work stress on headache prevalence: a longitudinal modelling study from the GAZEL cohort. Cephalalgia 2011, 31(6):696-705.

23. Fichera LV, Andreassi JL: Stress and personality as factors in women's cardiovascular reactivity. Int J Psychophysiol 1998, 28:143-155.

24. Abbate-Daga G, Fassino S, Lo Giudice R, Rainero I, Gramaglia C, Marech L, Amianto F, Gentile S, Pinessi L: Anger, depression and personality dimensions in patients with migraine without aura. Psychother Psychosom 2007, 76:122-128.

25. Haimanot RT: Burden of headache in Africa. J Headache Pain 2003, 4:S47-S54.

26. Vinding G, Zeeberg P, Lyngberg A, Nielsen R, Jensen R: The burden of headache in a patient population from a specialized headache centre. Cephalalgia 2007, 27(3):263-270.

27. Von Korff M, Stewart WF, Simon D, Lipton RB: Migraine and reduced work performance: A population-based diary study. Neurology 1998, 50(6):1741-1745.

28. Mengistu G, Alemayehu S: Prevalence and burden of primary headache disorders among a local community in Addis Ababa, Ethiopia. J Headache Pain 2013, 14(1):30.

29. Takele GM, Tekle Haimanot R, Martelletti P: Prevalence and burden of primary headache in Akaki textile mill workers, Ethiopia. J Headache Pain 2008, 14:119-128.

30. Haimanot RT: Headache in the Tropics: Sub-Saharan Africa. In Handbook of Headache: Practical Management. Edited by Martelletti P, Steiner T. Milan: Springer; 2011:533-540.

doi:10.1186/1746-160X-10-48

Cite this article as: Onwuekwe et al: Headache prevalence and its characterization amongst hospital workers in Enugu, South East Nigeria. Head \& Face Medicine 2014 10:48

\section{Submit your next manuscript to BioMed Central and take full advantage of:}

- Convenient online submission

- Thorough peer review

- No space constraints or color figure charges

- Immediate publication on acceptance

- Inclusion in PubMed, CAS, Scopus and Google Scholar

- Research which is freely available for redistribution 